\title{
Product formation by a nitrogen limited culture of Beneckea natriegens in a chemostat in the presence of excess glucose
}

\section{J. D. Linton' and S. C. Musgrave ${ }^{2}$}

\footnotetext{
I Shell Research Limited, Sittingbourne Research Centre, Sittingbourne, Kent, ME9 8AG

'Department of Applied Biology, University of Wales, Institute of Science and Technology, Cardiff. Great Britain
}

Eur J Appl Microbiol Biotechnol (1983) 18:24-28

The first two lines of Table 1 on page 26 should read:

\begin{tabular}{|c|c|c|c|c|c|c|}
\hline Dilution rate $\left(\mathrm{h}^{-1}\right)$ & 0.04 & $0.04+\mathrm{CCCP}^{*}$ & 0.10 & 0.27 & 0.45 & 0.66 \\
\hline Glucose conc. $\left(g \cdot 1^{-1}\right)$ input & 45.63 & 40.06 & 34.63 & 19.88 & 20.50 & 19.75 \\
\hline output & 4.49 & 3.46 & 2.75 & 2.59 & 6.6 & 8.23 \\
\hline
\end{tabular}

